\title{
Kalıpların Dışına Çıkmak: Yetkinlik Odaklı Muhasebe Ĕğitimi*
}

\author{
R. Şebnem YAŞAR ${ }^{* *}$
}

\begin{abstract}
ÖZET
Muhasebe eğitiminin temel hedefi, öğrencilere başarılı bir mesleki yaşama sahip olmak için gerekli yetkinlikleri kazandırmaktır. Farklı yetkinliklerin varlığı, çalışma ortamında karşılaşılan zorlukların çözümünde farklı yönlerden yardımcı olduğu için ișverenler tarafindan gerekli görülmektedir. Bir bașka ifadeyle ișverenler, mesleki teknik bilginin yanı sıra "kalıpların dışında" düşünebilen, iletişim, takım çalışması, liderlik gibi becerilere sahip kişileri tercih etmektedirler. Bu durum, muhasebe mezunlarının sahip oldukları yetkinlikler ile potansiyel işverenleri tarafindan aranan yetkinlikler arasında bir uyuşmazlık olup olmadığı konusunu gündeme getirmektedir.

Günümüzde muhasebe, artık sadece bir destek fonksiyonu olarak görülmemekte, kurumsal performans yönetiminde etkin rol almaktadır. Bu dönüşüm, mesleki başarının belirleyicilerini de etkilemektedir. Bu bağlamda, muhasebenin değer önerisine, bir başka ifadeyle muhasebe çalıșanlarının ișletmelere nasıl değer kattığına ilișkin stratejik bir bakış açısı geliștirilmeli ve üniversitelerde bu değer önerisine dayalı müfredatlar olușturulmalıdır. Bu çalışmada muhasebenin değişen rolünün muhasebe eğitimine etkileri, mevcut muhasebe eğitim sürecindeki sorunlar ve yetkinlik kazanımının eğitim sürecine entegrasyonu incelenmiştir. Çalışma, literatür taramasına dayalı nitel bir çalışmadır ve muhasebe eğitimine yönelik eleştiriler vurgulanarak, muhasebe ĕgitiminde değişimin artık kaçınılmaz olduğu sonucuna varılmıştır.
\end{abstract}

Anahtar Kelimeler: Muhasebe Eğitimi, Yetkinlik Odaklı Muhasebe Ĕ̆itimi, Muhasebe Yetkinlikleri.

JEL Sinıflandırması: M40, M41

\section{Going Outside the Box: Competency-Focused Accounting Education}

\section{ABSTRACT}

The main aim of accounting education is to provide students the competencies necessary to have a successful professional life. The existence of different competencies is demanded by employers as it helps in different ways in solving challenges in the workplace. In other words, besides having professional technical knowledge, employers prefer people that can "think outside the box" with skills such as communication, teamwork, leadership. This raises the question of whether there is a conflict between the competencies of accounting graduates and the competencies sought by potential employers.

Today, accounting is no longer appears to be a support function, but it plays an active role in enterprise performance management. This transformation has great influence in defining the determinants of professional success. In this context, a strategic perspective on the accounting's value proposition, that is, how accountants add value to the organizations should be developed and curricula based on this value proposition should be established in universities. In this study, the effects of changing role of accounting on accounting education, the problems in existing accounting education process and integration of competence acquisition into education process are examined. The study is a qualitative study based on literature review and by emphasizing criticism on accounting education it is concluded that the change in accounting education has become inevitable.

Keywords: Accounting Education, Competency-Focused Accounting Education, Accounting Competencies

Jel Classification: M40, M41

Makale Gönderim Tarihi: 03.05.2018

Makale Kabul Tarihi: 23.05.2018

\footnotetext{
* Bu makale, 18-22 Nisan 2018 tarihinde Antalya'da düzenlenen 37. Muhasebe Eğitimi Sempozyumu'nda sunulmuş olan bildirinin genişletilmiş tam metnidir.

** Doç. Dr., Dokuz Eylül Üniversitesi, İzmir Meslek Yüksekokulu, sebnem.yasar@deu.edu.tr, ORCID ID: 00000001-6173-5148
} 


\section{GİRIŞ}

Yönetim bilimi açısından yetkinlik, "çalışanların kendi işlerinde başarılı performans göstermelerine olanak sağlayan kişisel yetenekleri, bilgi, tecrübe ve beceri birikimleri" şeklinde tanımlanmaktadır. Boyatzis (2008: 6), yetkinlikleri "bir işte etkin ve/veya üstün performans sonuçları veren, kişiye ait temel özellikler" şeklinde tanımlamıştır. Dünyadaki bireysel, toplumsal, ekonomik ve teknolojik değişim ve gelişim, kaçınılmaz olarak iş piyasasının beklenti ve ihtiyaçlarında, buna bağlı olarak da istihdam edilecek meslek elemanlarında bulunması istenen yetkinliklerde değişim yaratmıştır.

İş piyasasının muhasebe meslek elemanlarında aradıkları nitelikler, muhasebe alanında eğitim veren kurumları yakından ilgilendirmektedir. Yetkinlik odaklı eğitim, eğitim süreci boyunca sistematik olarak geliştirilmesi hedeflenen yetkinliklerin öğrencilere kazandırılması üzerine odaklanmaktadır. Bu çalışmada, önce küreselleşen dünyada muhasebenin değişen rolü üzerinde durulmuş ve buna bağlı olarak muhasebe eğitiminde değişim ihtiyacı incelenmiştir. Daha sonra muhasebe yetkinlikleri, bu yetkinlikler bağlamında mevcut muhasebe eğitim sürecindeki sorunlar ve yetkinlik kazanımının eğitim sürecine entegrasyonu ele alınmıştır.

\section{MUHASEBENIN DEĞISSEN ROLÜ}

Günümüz iş ortamını değiştiren en önemli itici güçlerden biri, ister hızlı, daha az maliyetli ve kolaylıkla bilgi üreten donanımlar olsun, ister verilerin hazırlanmasını, yayılmasını ve iletişimini kolaylaştıran yazılımlar olsun, teknolojinin, özel olarak bilgi teknolojilerinin hızlı gelişimidir. Teknolojideki bu gelişim, bilginin kullanılabilirliğine yönelik kısıtlamaları azaltmış ve çoğu durumda ortadan kaldırmıştır. İkinci temel etken, mesafe ve sınırları anlamsız hale getiren küreselleşmedir. Daha hızlı ulaşım, iletişim ve anında bilgi edinilebilmesi sayesinde dünya dev bir pazar haline gelmiștir (Mohamed ve Lashine, 2003: 5). Bu değişiklikler yalnızca iş ortamını tamamen değiştirmekle kalmamış, muhasebe mesleği ve dolayısıyla muhasebe eğitimi üzerinde önemli yansımalar oluşturmuştur. Böyle bir değişim ve gelişim döneminde, "kayıt tutucu" olarak tanımlanan geleneksel muhasebecinin, bu rolüyle artık işletmeye yeterli katkıda bulunmadığı ortadadır. Ticari bilgi tedarikçileri olan muhasebecilerin rolü, artık "bilgi uzmanları" olarak işletmeleri ileriye götürmeye yardımcı olmaktır (Jackling ve De Lange, 2009: 369).

Hood (2015) muhasebe mesleğini doğrudan etkileyen "üç büyük kâbusa" dikkat çekmekte ve bunları, "mesleğin uzun süredir yerine getirilen temel hizmetlerinin değerini düşüren teknoloji kaynaklı değişiklikler", "doğru yetkinliklere sahip yeni çalışanlar bulmak ve mevcut çalşsanları yeniden eğitmek" ve "teknolojinin değişim hızına ayak uydurmak" olarak sıralamaktadır. Teknolojik gelişmelerin muhasebe mesleği üzerindeki etkisi, bazı faaliyetlerin maliyetleri düşürmek amaciyla başka ülkelere kaydırılmasında ve muhasebe faaliyetlerinde otomasyonunun arttrilmasında görülebilmektedir. Otomasyon, muhasebe çalşsanlarındaki yetkinlik eksikliğini daha görünür hale getirmiştir (Pincus vd., 2017: 7). Frey ve Osborne (2014: 28) bu durumu, "bir bilgisayarın işinizi elinizden almasına engel olmak istiyorsanız, yaratıcı ve sosyal becerilerinizi geliştirmelisiniz" şeklinde ifade etmişlerdir. PricewaterhouseCoopers (2015: 1) teknolojinin denetim şirketlerinde üst düzey teknik becerilere duyulan ihtiyacı azalttığını belirtmiş ve "denetim alanında kariyer yapmayı hedefleyen bireylerin, onlardan beklenecek olan farklı yetkinlikler için hazırlıklı olmaları gerektiğini" vurgulamışlardır. 
Finansal raporlamadan sorumlu muhasebe çalışanları, giderek daha karmaşık hale gelen gereksinimlere cevap verebilmek için ticari işlemlerin ekonomik içeriklerini analiz etme konusundaki geleneksel yükü taşımaya devam etmektedir. Buna ek olarak, risk raporlaması, performans ölçümleri ve sürdürülebilirlik raporlaması gibi yeni görevler oluşmuştur. Bu yeni sorumluluk alanları, raporlama yetkinliğinin daha geniş bir tanımını gerektirmekte ve muhasebecilere risk, işlemlerin yapılandırılması ve performans ölçümlerinin kapsamının genişletilmesiyle ilgili konular hakkında üst yönetime tavsiyelerde bulunma firsatı sağlamaktadır (Lawson vd., 2014: 299).

Groysberg vd. (2011: 64), üst düzey finansal yöneticilerin görevlerinin geleneksel bütçeleme ve geçmiş performans değerlendirmelerinden, çevredeki değişikliklere hızlı ve stratejik cevaplar verebilmek için gerekli olan verilerin gerçek zamanlı analizine doğru genişlediğine ve yöneticilerin geniş kapsamlı teknik yetkinliklere ve işletme yönetiminin temellerini anlamaya gereksinim duyduklarına dikkat çekmektedir. Son yıllarda yükselişte olan iş analizi ve iş zekâsı gibi alanlar, muhasebe çalışanlarının, strateji uygulama ile doğrudan ilgili olanlar da dahil olmak üzere daha geniş çaplı iş kararlarına dahil olmalarına olanak tanımaktadır (Lawson vd., 2014: 299). Bir başka ifadeyle muhasebe çalışanları, yöneticilere bilgi aktaran destek odaklı personelden, örgüt genelindeki yöneticilerle birlikte "masada yeri" olan personele evrilmiştir (Brewer vd., 2014: 30). Muhasebe çalışanları artık paydaşlara değer katan stratejileri formüle ederek planlama süreçlerine katılmaktadırlar. Bir destek işlevinden bir kurumsal performans yönetimi rolüne yönelim, meslekte başarıyı sağlayan unsurları da büyük ölçüde etkilemiştir.

\section{MUHASEBE EĞITIMINDE DEĞIŞiM İHTIYACI}

Küreselleşme, yeni ekonomik koşullar, bilgi teknolojilerindeki hızlı gelişmeler ve çok yönlü beceri gereksinimi, günümüz işletmelerinin karşı karşıya olduğu zorluklardan sadece bazılarıdır. Bu hızlı değişim, iş hayatına adım atacak mezunların hazırlandığı ortamların da değişmesi gerektiği anlamına gelmektedir (Mohamed ve Lashine, 2003: 3).

Uluslararası kabul görmüş Bedford Komitesi'nin (1986) “Gelecekteki Muhasebe Eğitimi: Değişen Mesleğe Hazırlık” raporunun yayınlanmasının ve ardından ABD'de Muhasebe Eğitimi Değişim Komisyonunun (1990) kurulmasından itibaren meslek mensupları ve eğitimciler, muhasebe eğitiminde önemli değişiklikler yapılmasının gerekliliğini tartışmaktadırlar. Mesleğe ilk adımlarını atan yeni mezun muhasebe çalışanlarının giderek karmaşıklaşan ve sürekli değişen yetkinlik taleplerine cevap verme ihtiyacı hem muhasebe eğitimcileri hem de meslek mensupları tarafından çözülememiş bir sorunu temsil etmektedir (French ve Coppage, 2003: 107).

Çağdaş küresel dünyada, muhasebe ve muhasebe eğitiminin anahtar bir rolü, kamu yararı için işletmelerin hesap verebilirliğini ve sosyal sorumluluğunu geliştirmektir. Bu ortamda, işletmelerin ve ilgili muhasebe faaliyetlerinin ekonomik, sosyal ve ahlaki etkilerinin farkına varılması, muhasebe eğitimi için yeni sorunlar oluşturmaktadır. Son yıllarda muhasebe eğitiminde çok çeşitli eleştirel ve analitik becerilerin geliştirilmesine odaklanılması için birçok çaba sarf edilmesine rağmen, muhasebe araştırmaları ve eğitiminde ana akım, bağlamdan koparılmış, teknisyen ve pozitivist yaklaşımları yansıtmaya devam etmektedir (Boyce vd., 2012: 49). 
Humphrey (2005: 348), "muhasebe meslek mensuplarının eğitimine ciddi anlamda akademik özen gösterilmesi" ve "değişim arayışının çok yönlü bir anlayışla ve kademeli bir şekilde ele alınması gerektiğini" ileri sürmektedir. Geleneksel muhasebenin sınırları dışına çıkmak, muhasebe teknik yetkinliğini, muhasebenin tarihsel, sosyal, politik ve uluslararas1 etkilerine göre tamamlayarak ögrencileri, iş dünyasının içindeki ve dışındaki olaylara hazırlayabilecektir. $\mathrm{Bu}$ süreç zorunlu olarak "günlük hayatın etkileşimiyle muhasebe arasındaki ilişkinin ve bunların daha büyük sosyal sistemle arasındaki bağlantının" anlaşılmasını içermektedir (Boyce vd., 2012: 50). Teknik yetkinlikler ile muhasebenin kültürel ve toplumsal bağlamının karışımı, yalnızca iyi donanımlı ve çok yönlü mezunlar üretmekle kalmaz aynı zamanda öğrencilerin ekonomik çıkarlarına da hizmet eder. $\mathrm{Bu}$ beceriler, işverenler tarafindan yüksek oranda değer verilen ve yüksek maaş beklentileri ile sonuçlanabilecek, ancak muhasebe mezunlarında genellikle eksik olan yetkinliklerdir.

Yeni küresel iş modelleri ve dijital çağ, muhasebe çalışanlarından beklentileri değiştirmiştir. 20 yıl öncesine kadar, birçok muhasebe mezununun işyerlerindeki başarıları, sahip oldukları uzmanlık bilgisine, bir başka ifadeyle teknik yetkinliklerine bağlıydı. Daha yakın tarihli araştırmalar ise teknik yetkinliklerin iddia edildiği ölçüde başarının anahtarı olmadığını, kariyer başarısı ile ilişkili olan yetkinliklerin esas olarak, bir görevden diğerine aktarılabilir nitelikteki genel yetkinlikler olduğunu öne sürmektedir (Jackling ve De Lange, 2009: 371). Bu yetkinlikler genellikle iletişim, takım çalışması, liderlik ve analitik düşünme gibi becerilere hâkimiyeti içermektedir. Foley (2007: 52), muhasebe çalışanlarında insani yetkinliklere verilen önemi artıran ve bunları teknik yetkinliklerle aynı seviyede tutan olumlu bir paradigma kayması olduğunu ifade etmektedir.

Üniversiteler, teknik bilgi anlamında donanımlı ancak iş hayatına hazır olmayan muhasebe mezunları oluşturdukları için sıklıkla eleştirilmektedirler (Howieson vd., 2003: 100; Siegel vd., 2010: 41). Sonuç olarak, birçok araştırmacı, muhasebe öğrencilerine öğretilenlerle uygulamada yapılanlar ve profesyonel iş hayatının gerektirdiği beceriler arasında önemli bir boşluk bulunduğunu ileri sürmektedirler.

Teknik olmayan yetkinliklerin geliştirilmesine duyulan ihtiyaç, eğitimin sağladıkları ile işveren beklentileri arasındaki "uyuşmazlıkları" belirleyen birtakım çalışmalarla sonuçlanmıştır. Örneğin, Siegel ve Sorensen (1994: 14) üniversitelerin işveren beklentilerini karşılayacak şekilde öğrencileri hazırlayamamalarını "hazırlık uyuşmazlığı" olarak ifade etmişlerdir. Milner ve Hill (2008: 13), iletişim ve problem çözme becerilerinin eksikliğine odaklanarak, bunu "beceri uyuşmazlığı" olarak adlandırmışlardır. Siegel vd. (2010: 43), ABD'deki üniversitelerde yaptıkları bir çalışma sonucunda, çoğu lisans dersi 25 yıldır değiştirilmediği için muhasebe müfredatının pazar talepleriyle uyuşmadığını belirterek "senkronizasyon uyuşmazlığı" belirlemişlerdir. Bui ve Porter (2010: 24) ise, işverenlerin beklentileri ile öğrencilerin sahip olması gereken yetkinliklerin algılanışı arasında bir boşluk olduğu sonucuna varmışlar ve bunu "beklenti-performans uyuşmazlığı" olarak ifade etmişlerdir.

Çeşitli paydaşların yükseköğrenimde genel yetkinlikleri geliştirme çabalarına rağmen, bazı araştırmacılar üniversitelerin, mezunların işverenlerin taleplerini karşılamak için gerekli genel becerilere sahip olmasını garanti etmenin gerçekçi olmadığını savunmaktadırlar. Clanchy ve Ballard (1995: 158), en iyi ihtimalle üniversitelerin sadece, öğrencilere lisans eğitimi süresince genel becerileri ve yetenekleri öğrenme ve geliştirme firsatı sunmayı garanti 
edebileceklerini ifade etmişlerdir. Üniversitelerin genel yetkinliklerin geliştirilmesine katkısını inceleyen Cranmer (2006: 182), bu becerilerin sınıfta etkili bir şekilde geliştirilebileceği varsayımına şüpheyle yaklaşmaktadır. Üniversitede genel yetkinliklerin geliştirilmesinin zor olduğu fikri, Lucas vd.'nin (2004) çalışmaları tarafından desteklenen bir görüştür. Yazarlar, İngiltere'de nitel bir çalışmanın sonuçlarını ortaya koymuşlar, genel yetkinlik gelişiminin hayat boyunca gelişen örtülü bir süreç olduğunu ve yalnızca bağımsız modüllerle geliştirilemeyeceğini iddia etmişlerdir. (Lucas vd., 2004: 66).

Sorun, mezunların önemli genel yetkinliklere sahip olmadığı görüşünde büyük oranda kendini göstermektedir. Mezunlardan, mesleki teknik bilgiden çok daha fazlasına sahip olmaları beklenmektedir ve bu bağlamda muhasebe eğitiminde değişim, bir zorunluluk olarak kendini göstermektedir (Gammie vd., 2002: 63).

\section{MUHASEBE YETKİNLIKKLERI}

Muhasebe eğitiminde kazandırılan yetkinliklerin teknik alanın ötesine genişletilmesi, özellikle işverenler tarafından sıklıkla vurgulanmaktadır. Bui ve Porter (2010: 26), muhasebe yetkinliklerini, işlevsel yetkinlikler (teknik muhasebe uzmanlığı), genel işletme yetkinlikleri (işletme yönetimine ilişkin temel bilgiler) ve kişisel yetkinlikler (iletişim, liderlik, değişime uyum yeteneği, vb.) olarak özetlemektedir.

AICPA (Amerikan Yeminli Mali Müşavirler Enstitüsü), Tablo 1'de gösterilen üç temel yetkinlik kategorisi belirlemiştir. Bunlar, işlevsel (muhasebe) yetkinlikler, bireysel (mesleki) yetkinlikler ve iş yetkinlikleridir.

Tablo 1. AICPA'nın Muhasebe Yetkinlikleri Kategorileri

\begin{tabular}{|l|l|l|}
\hline İşlevsel Yetkinlikler & Bireysel Yetkinlikler & İş Yetkinlikleri \\
\hline Risk değerlendirme, analizi ve & Etik davranış & Stratejik perspektif \\
\hline Veri analizi ve yorumlama & Profesyonel tutum & Sektörel ve küresel perspektif \\
\hline Raporlama & Profesyonel yargıda bulunabilme & Süreç ve kaynak yönetimi \\
\hline Araştırma & İşbirliği & Yönetişim perspektifi \\
\hline Sistem ve süreç yönetimi & Liderlik & Müşteri perspektifi \\
\hline Teknoloji kullanımı & İletişim & \\
\hline & Proje yönetimi & \\
\hline
\end{tabular}

https://www.aicpa.org/interestareas/accountingeducation/resources/accounting-core-competencies-functional.html; https://www.aicpa.org/interestareas/accountingeducation/resources/accounting-core-competencies-personal.html; https://www.aicpa.org/interestareas/accountingeducation/resources/accounting-core-competencies-business.html

AAA (Amerikan Muhasebe Birliği), muhasebe eğitimine ilişkin görüş ve projeksiyonlarının yer aldığı Pathways Komisyonu Raporu'nda (2012, 132 -133) yetkinlikleri üç kategoride toplamıştır. Bunlar; teknik bilgi, mesleki yetenekler ile mesleki doğruluk ve sorumluluktur.

CPA Canada (Kanada Serbest Muhasebeci ve Mali Müşavirler Birliği) ise bir mali müşavirde olması gereken yetkinlikleri iki gruba ayırmıştır. Bunlarda birincisi, finansal 
raporlama, strateji ve yönetişim, yönetim muhasebesi, denetim, finans ve vergi konularında becerileri kapsayan "teknik yetkinlikler"dir. İkincisi ise, mesleki ve etik davranış, problem çözme ve karar verme, iletişim, öz yönetim ile ekip çalışması ve liderlik konularındaki becerileri kapsayan “etkinleştirici yetkinlikler”dir (CPA Canada, 2012).

Lawson vd. (2014) muhasebe yetkinliklerini, "temel yetkinlikler", "genel yönetim yetkinlikleri" ve "muhasebe yetkinlikleri" olarak üç gruba ayırarak, bu yetkinliklerin birbiriyle olan bağlantılarını ve etkileşimlerini gösteren bir çerçeve oluşturmuşlardır. Yetkinliklerin, eğitim, staj ve iş tecrübesi kombinasyonu yoluyla zaman içinde geliştiği ve entegre olduğunu varsayılmaktadır. Çerçevenin odak noktasını, derslerin değil yetkinliklerin geliştirilmesi oluşturmaktadır. $\mathrm{Bu}$ yetkinlikler, finansal muhasebe, maliyet muhasebesi, yönetim muhasebesi, vergi işlemleri, bilgi sistemleri ve denetim dahil olmak üzere tüm muhasebe disiplinlerinden gelen kapsamlı ve kapsayıcı yetkinliklerdir ve muhasebe öğrencilerinin uzun vadeli kariyerleri için eğitim ihtiyaçlarına odaklanmaktadır (Lawson vd., 2014: 299). Lawson'un yetkinlik çerçevesi Tablo 2'de gösterilmektedir.

Tablo 2. Lawson vd.'nin yetkinlik çerçevesi

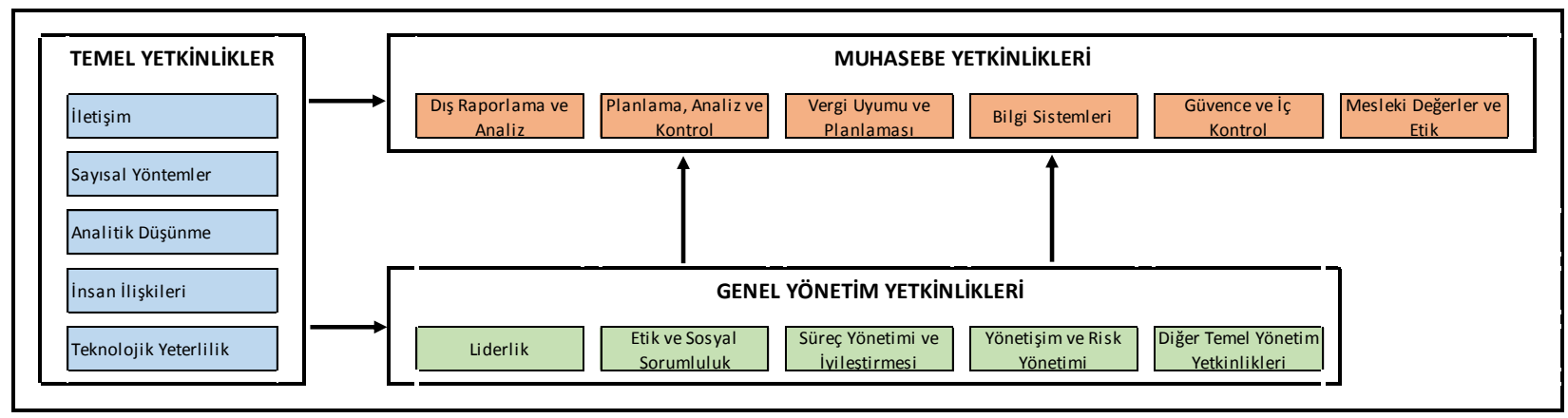

Kaynak: Lawson vd., 2014: 299

Bu yetkinliklerin kapsamları aşağıda açıklanmaktadır (Lawson vd., 2014: 301-303).

- Temel Yetkinlikler: Temel yetkinlikler, genel yönetim ve muhasebe yetkinliklerinin dayandığ 1 temeli oluşturmaktadır. Bu yetkinlikler öğrencileri hayat boyu sürecek kariyer için hazırlarlar. Temel yetkinlikler, iletişim, sayısal yöntemler, analitik düşünme, insan ilişkileri ve teknolojik yeterlilik olmak üzere beş temel yetkinliği içermektedir. Bu yetkinliklere sahip olmak, gelecekte çalışacakları örgütlere değer katmak için tüm muhasebe çalışanları için gereklidir.

- Genel Yönetim Yetkinlikleri: Muhasebe profesyonelleri de dahil olmak üzere iş dünyası profesyonellerini yetiştirme iddiasında olan bir eğitim modeli, öğrencilerin geniş kapsamlı entegre yönetim yetkinlikleri geliştirmelerinde yardımcı olmalıdır. Bu yetkinliklere sahip olmak, muhasebe çalışanlarının değer yaratmak için örgütün tüm üyeleri ile birlikte ve etkili bir şekilde çalışmalarına yardımcı olacaktır. Aslında bu yetkinlikler, başarılı bir yönetici olmak isteyenler için önemlidir. Çerçevede, liderlik, etik ve sosyal sorumluluk, süreç yönetimi ve iyileştirmesi, yönetişim ve risk yönetimi ile diğer temel yönetim yetkinlikleri olmak üzere beş geniş kategori tanımlanmaktadır. Muhasebe eğitimi de dahil olmak üzere işletme eğitiminde, etkin örgütsel performans ve verimli kariyerler için entegre genel yönetim yetkinliklerinin kazandırılması gerektirmektedir. 
- Muhasebe Yetkinlikleri: Muhasebe yetkinlikleri, işletmenin stratejisini başarıyla formüle etmesine ve yürütmesine yardımcı olmak için, teknoloji destekli yönetim ve analitik yöntemlerin entegre edilmesini sağlar. Çerçeve, muhasebe yetkinliklerini, dış raporlama ve analiz; planlama, analiz ve kontrol; vergi uyumu ve planlaması; bilgi sistemleri, güvence ve iç kontrol ve mesleki değerler ve etik olmak üzere altı kategoriye ayırmaktadır.

\section{YETKINLIKLERIN ENTEGRASYONU}

Muhasebe yetkinliklerinde ustalık yetkinliğin kendisi ile başlamakta ve daha sonra diğer yetkinliklerle entegrasyona uzanmaktadır. Yetkinlik entegrasyonuna olan ihtiyaç, muhasebe alanının karmaşıklığı arttıkça artmaktadır.

Lawson vd. (2015: 151), yetkinliklerin entegrasyonuna ilişkin dört seviyeli bir model önermişlerdir. Bu modeldeki birinci entegrasyon seviyesi, muhasebe müfredatlarındaki temel yetkinliklerin rolü ile ilgilidir. Adından da anlaşılacağı üzere bu yetkinlikler gerçek anlamda temeldir. Öğrenciler diğer insanlarla birlikte üretken bir şekilde çalışamıyorlarsa, etkin iletişim kuramıyorlarsa, sorunları analiz etmek ve çözmek için teknoloji ve temel nicel yöntemlerden yararlanamıyorlarsa muhasebe mesleğinin kurumsal performans yönetimi değer teklifi anlamsızlaşır. Temel yetkinlikler muhasebe eğitimine entegre edilmelidir.

İkinci seviye, farklı konuların tek bir muhasebe yetkinliği içerisinde bütünleştirilmesidir. Örneğin, "Dış Raporlama ve Analiz” yetkinliğini kazandırmak için, örneğin gelir tahakkuku ve gelecekteki yükümlülükler için karş1lık ayırma konuları öğretilmektedir. Bu iki konu, öğrencilerin işlem döngüsündeki gelirlerin ne zaman tahakkuk edileceğini belirlemeleri ve daha sonra tamamlanmış bir satış işlemiyle eşleştirilmesi gereken gelecekteki garanti sorumluluğunu tahmin etmeleri yoluyla entegre edilebilirler. "Planlama, Analiz ve Kontrol" yetkinliği kapsamında yer alan iki konu olan bütçeleme ve esnek bütçe sapma analizleri, öğrencilerin önce bir ana bütçe hazırlamaları, daha sonra aynı işletme için esnek bütçe çalışması yaparak sapmalarını hesaplamaları istenerek birleştirilebilir (Lawson vd., 2015: 151).

Yetkinlik entegrasyonunun üçüncü seviyesi, birden fazla muhasebe yetkinliği arasında gerçekleşir. Örneğin, "Dış Raporlama ve Analiz" ile "Planlama, Analiz ve Kontrol" yetkinlikleri arasındaki entegrasyon, bir kuruluşun ana bütçesinin bir parçası olarak hazırlanan nakit bütçesiyle diş raporlama amacıyla hazırlanan nakit akış tablosunun karşılaştırılması yoluyla elde edilebilir. Bu tabloların görüntüsü farklı olsa da her ikisi de tarihi veya öngörülen nakit akışlarını ana kategorilere, kaynaklara veya kullanımlara göre özetlemekle aynı temel amaca hizmet etmektedir (Lawson vd., 2015: 151).

Son entagrasyon seviyesinde, temel yetkinlikler ve muhasebe yetkinlikleri, genel yönetim yetkinlikleriyle bütünleşir (Lawson vd., 2015: 152). Örneğin, uluslararası transfer fiyatlandırmasıyla ilgili yetkinlik entegrasyonu, "Vergi Uygunluğu ve Planlaması" yetkinliği kapsamındaki yasaların uygunluğuna ilişkin bir vergi politikası konusuyla bağlantılı olarak vergi yasalarının incelenmesini gerektirebilir. Konu, bir konsolide finansal raporlama görevi dahil edilerek "Dış Raporlama ve Analiz" yetkinliğinin entegrasyonu ve daha sonra "Yönetişim, Risk ve Uyum" genel yönetim yetkinliğinin dahil edilmesi ile daha da genişletilebilir. 


\section{YETKINLLIKLER BAĞLAMINDA MUHASEBE EĞITIMINDEKI SORUNLAR}

Muhasebe programlarının tasarımı, öğrencilerin muhasebe mesleğinin ihtiyaçlarını karşılama becerilerini geliştirmeye odaklanmalıdır (French ve Coppage, 2003: 111). Yetkinlikler bağlamında muhasebe eğitimindeki sorunlu alanlar; ders içerikleri ve müfredata ilişkin sorunlar, pedagojik sorunlar ve teknoloji kullanımına ilişkin sorunlar olmak üzere üç kategoride incelenmiş̧ir.

\subsection{Ders İçerikleri ve Müfredata İlişkin Sorunlar}

Eğitim modellerimiz, öğrencilerin başarılı profesyoneller olabilmesi için gerekli yetkinliklerin geliştirilmesi yerine büyük ölçüde içeriğe odaklanmaktadır. Öğrenmenin ezbere dayalı ve yüzeysel biçimlerine yapılan aşırı vurgu ve öğrencilerin entelektüel, etik, yansitıcı ve eleştirel kapasitelerinin geliştirilmesine yeterli önem verilmemesi, muhasebe eğitiminde en çok eleştirilen konuların başında gelmektedir (Gray ve Collison, 2002: 814). Öğrencilerin ve uygulamacıların dile getirdiği bir husus, muhasebe derslerinin, bilginin çoklu kaynaklardan nasıl elde edildiği veya bilgiyi işin daha geniş bağlamında kullanılması konusunda açık bir anlayış geliştirilmeden, çok miktarda bilginin ezberlenmesini vurgulamasıdır (French ve Coppage, 2003: 111). Albrecht ve Sack (2000: 55), şu ifadeleri kullanmışlardır: "Öğrenciler ezberledikleri şeyi unuturlar. İçerik bilgisi güncelliğini kaybedebilir ve genellikle farklı görevler arasında aktarılabilir değildir. Öte yandan, önemli yetkinlikler, farklı görevler ve farklı işler arasında genellikle devredilebilir. Muhasebe eğitimi, içerikte yeterliliğe çok fazla zaman ayırdığı için eleştirilmektedir ve öğrencilerin hayatlarını zenginleştirecek ve başarılı olabilecek yetkinlikler geliştirmelerine yardımcı olmak için çok az zaman ve çaba harcamaktadır."

Muhasebe, hala bilginin maliyetli olduğu şeklinde öğretilmektedir. Oysa günümüzde bilgi ucuzdur ve müfredatımızın bilgi toplama ve kaydetmeye ayrılan kısmı zaman kaybıdır. Eğitim modellerinin önemli bir parçası olan bilgi işleme, artık doğru yazılımı kullanan herkes tarafindan hızlı bir şekilde yönetilebilmektedir. Geleneksel muhasebe programları iyi bir muhasebeci oluştururken, iş dünyası işletmeye katma değer sağlayacak çok yönlü bir çalışan istemektedir. Ders içerikleri, mesleğin temel yetkinlikleriyle uyuşmamaktadır. Bu konuda en yaygın eleştirilerden bazıları şunlardır (Albrecht ve Sack, 2000: 53):

- Dersler genellikle bir dizi teknik kuralın öğretilmesine dayanmaktadır.

- Müfredatlar ve ders içerikleri, doğru cevaba ulaşmaya çok fazla odaklanmaktadır.

- Müfredat çok dar kapsamlıdır ve çoğu kez çağın gereksinimlerini karşılamamaktadır. Öğrencilere geniş kapsamlı bir işletme eğitimi verilmemektedir ve yeterli gerçek hayat örnekleri kullanılmamaktadır.

- Öğrenciler, küreselleşme, teknoloji ve etik gibi günümüz iş dünyasıyla oldukça ilişkili kavramlarla doğru şekilde buluşturulamamaktadır.

- Muhasebecilerin ne yapacaklarından çok ne yaptıkları öğretilmektedir. 
- Programlar, öğrencilerin başarılı olmalarını sağlayacak kritik yetkinliklerin kazandırılması yerine, içerik temelli derslere odaklanmaktadır.

- Birinci sınıf öğrencilerine muhasebecilerin ne yaptıklarına dair yanlış izlenim verilmektedir. Bu durum genellikle defter tutma ve kural tabanlı yönlenimi ögrencilerde kalıcı hale getirmektedir.

- Teknolojinin iş dünyasını nasıl şekillendirdiği öğrencilere öğretilmemektedir.

\subsection{Pedagojik Sorunlar}

Eğitimin amacı belirli bir içeriği öğretmek değil, öğrencilere yeni deneyimler yoluyla nasıl düşüneceklerini ve yönlerini nasıl belirleyeceklerini öğretmek olmalıdır. Böylece, karşılarına çıkacak sorunları ve olayları kolayca ve hızlı bir şekilde kavramalarını sağlayacak bir anlayışa ve algıya sahip olacaklardır. Albrecht ve Sack (2000: 53), muhasebe eğitiminin pedagojik sorunlarını aşağıdaki gibi özetlemişlerdir:

- Kural temelli ve ezbere dayalı eğitim modeli ve hatırlama üzerine yapılandırılmış sınavlar yetersizdir, ancak daha da önemlisi, öğrencileri iş dünyasının belirsizliğine hazırlamamaktadir.

- Uygulanan pedagojik yöntemler genellikle yaratıcılıktan yoksundur, çok fazla ders anlatımı ve ders kitaplarına bağımlılık içermektedir. Dolayısıyla öğrencilerin öğrenme yeteneği gelişmemektedir. Eğitim ders saatleriyle sınırlıdır ve öğrencilerin iş dünyasıyla yeterince bağlantı kurmaları gerekli görülmemektedir. vardir.

Ders içeriklerinin yetersiz olmasının yanı sıra bu içerikleri verme şeklinde de sorunlar

- Takım çalışması, gerçek şirketlere ilişkin ödevler, olay analizleri, sözlü sunumlar, rol oynama, teknoloji kullanımı, videolar, yazılı ödevler, hizmet içi öğrenim, uygulamacıları ve yöneticileri derslere davet etme, güncel olayları inceleme gibi yaratıcı ögrenme türlerini geliştirmek konusunda isteksiz davranılmaktadır.

- Staj, saha çalışması, işletme gezileri, İnternet kullanımı, profesyonellerin gölgelendirilmesi gibi sınıf dışı deneyimler yeterli derecede kullanılmamaktadır.

Bu pedagojik sorunlar muhasebe eğitimine özgü değildir. Bununla birlikte, muhasebe standartlarının kullanımının yaygınlaşması, araştırma, analiz etme ve yorumlama becerilerini, ezberlemekten daha değerli hale getirmiştir ve bu durum muhasebe eğitimindeki sorunu daha da kötüleştirmektedir.

\subsection{Teknoloji Kullanımına İlişskin Sorunlar}

Teknoloji, yaşama ve çalışma şeklimizde köklü değişiklikler yaratmıştır. Buna rağmen öğrencilere, teknolojinin iş dünyasındaki etkisi ve karar alma sürecinde teknoloji kullanımıyla ilgili yeterli bilgi verilmemektedir. Slaytlar, elektronik tablolar ve veritabanları kullanmak teknolojinin yeterince kullanıldı̆̆ anlamına gelmemektedir. Teknolojinin bu yönlerini 
anlamak önem taşımakla birlikte, daha kritik olan nokta, teknolojinin yaptığımız her şeyi nasıl şekillendirdiğini anlamaktır.

\section{YETKINLLIK ODAKLI MUHASEBE EĞITTIMI}

Pathways Komisyonu (2012: 10), muhasebenin toplumdaki rolüyle ilgili kapsamlı bir anlayış geliştirilmesi gerekliliğini belirtmiştir. Bir başka deyişle, muhasebenin stratejik konumlandırılması yapılmalıdır. Bu çaba, muhasebenin değer önerisine, bir başka ifadeyle muhasebecilerin kuruluşlara nasıl değer kattığına ilişkin stratejik bir bakış açısı ve bu değer önerisine dayalı bir müfredat gerektirmektedir. Yapılan çalışmaların, genel yetkinlikler ile mesleki başarının açıkça bağlantılı olduğu önermesinde yoğunlaştığı görülmektedir. Muhasebe mezunlarında var olan genel yetkinliklerin yetersizliğini tanımlayan çalışmaların ardından, daha yeni araştırmalar, genel yetkinliklerin lisans derslerinde en iyi şekilde geliştirilme yollarını incelemektedir.

Genel yetkinliklerin geliştirilmesine yönelik planların ders içeriklerinde net bir şekilde ifade edilmesini ve bu yetkinliklerin derslerde gerçekten öğretilmesini sağlamak için, özellikle A.B.D., Kanada ve Avusturalya'da meslek kuruluşlarının baskıları görülmektedir. Örneğin, 110.000 üyeye sahip Avustralya Yeminli Mali Müşavirler Birliği, üniversiteleri, mesleki akreditasyonun bir parçası olarak, genel becerileri bir beceri matrisi kullanarak derslerine dâhil ettiklerini raporlamalarını istemektedir (Jackling ve De Lange, 2009: 371). Bu düşünce yapısına uygun olarak üniversiteler, eğitimde mükemmelliği teşvik etmeye ve topluma katkıda bulunmak için gerekli entelektüel kapasiteye sahip mezunlar sunmaya çalışan uygulamalar geliştirmişlerdir. Örneğin Avustralya Deakin Üniversitesi, Deakin Avantaj1 (Deakin Advantage) politikasıyla, bir Deakin mezununun niteliklerini tanımlamıştır. Deakin Avantajında tanımlanan birincil nitelikler, çeşitli paydaşların ihtiyaç duyduğu genel yetkinliklerin gelişimini desteklemeyi amaçlamaktadır.

Çok çeşitli becerilerin geliştirilmesi, yetkinlik odaklı muhasebe eğitiminin gereğidir. Muhasebe eğitimcileri bu becerileri muhasebe müfredatlarına dâhil etmeli ve etkinliğini sürekli olarak değerlendirmelidirler (French ve Coppage, 2003: 112). Yetkinlik odaklı muhasebe eğitimi için yapılması gereken değişiklikler; müfredat ve ders içeriklerine ilişkin değişiklikler, pedagojik yöntem değişiklikleri ve teknoloji kullanımına yönelik değişiklikler olmak üzere üç grupta incelenmiştir.

\subsection{Müfredat ve Ders İçeriklerinin Yeniden Yapılandırılması}

Üniversitelerde görev yapan öğretim elemanlarının temel rolü, muhasebe bilgisinin sınıftaki derslerde verilmesinden eğitim süreçlerini yönetmeye kaymaktadır. Bu bağlamda, öğretim elemanlarının sorumlulukları, süreç yöneticileri olarak artmıştır (French ve Coppage, 2003: 112-113). Öncelikle, öğretim elemanları muhasebe mesleğinde ihtiyaç duyulan yetkinlikleri değerlendirmeli ve bunları eğitim sürecine dâhil etmelidir. Öğretimde modası geçmiş yaklaşımları benimsemek yerine öğrenme sürecini en üst düzeye çıkaran doğru pedagojik model karışımını belirlemeli ve uygulamalıdırlar. Ayrıca, muhasebe meslek mensuplarıyla ve meslek kuruluşlarıyla iş birliği yaparak, muhasebe programlarının kalitesini ve işlevselliğini artırmak için çaba göstermelidirler. 
Öncelikle, bilgi edinme ve sınıfta problem çözme faaliyetlerine odaklanmak yerine, derslerin çeşitli teknik ve teknik olmayan becerilerin gelişimini içerecek şekilde genişletilmesi gerekmektedir (French ve Coppage, 2003: 112). Eğitimciler, analitik / eleştirel düşünme, yazılı iletişim, sözlü iletişim, bilgisayar teknolojisi, karar verme, kişiler arası beceriler, sürekli öğrenme, takım çalışması, liderlik, risk analizi ve müzakere gibi becerileri geliştiren bir strateji benimsemelidir. Lisans programları için müfredat tasarlanırken, dersler bir dizi teknik kural olarak öğretilmemeli, mesleki sınavlara odaklanılmamalı, gerçek hayattan örnekler kullanılarak ve küresel perspektifler vurgulanarak öğrenciler daha geniş iş alanlarına açılmalıdır. Eğitimciler, muhasebe elemanının gelecekte ne yapması gerekeceğine daha çok ağırlık vermeli, yani verileri kaydetmenin ötesinde analiz vurgulanmalıdır (Mohamed ve Lashine, 2003: 10).

Müfredatın ve ders içeriklerinin geliştirilmesi için aşağıdaki stratejiler önerilmektedir (Mohamed ve Lashine, 2003: 10).

- Seçmeli derslerin sayısı ve çeşitliliği arttırılmalıdır.

- Gerçek iş hayatındaki olay ve problemleri simüle eden ve bu problemleri çözmek için beceri ve yaklaşımların geliştirilmesini destekleyen olay analizleri kullanılmalıdır

- Staj programı sadece bir eğitim programı olarak değil, bir işletmenin karşılaştığ sorunları görerek işe katkıda bulunma firsatı olarak değerlendirilmelidir.

- Muhasebe eğitiminin müşteri odaklılığını artırmak için iş dünyasından kişiler müfredat tasarım komitelerine dahil edilmelidir.

- Müzakere becerileri, çatışma yönetimi ve kriz yönetimine ilişkin dersler yer almalıdır

Teknolojideki hızlı değişim nedeniyle gelişmelere ayak uydurmak için müfredatı güncellemek zorunludur. Bu bağlamda, müfredat tasarımının ve öğretim yöntemlerinin piyasa ihtiyaçlarına bağlı olarak periyodik olarak gözden geçirildiği değişim odaklı bir müfredat geliştirmek etkili bir strateji olabilir (Mohamed ve Lashine, 2003: 10).

\section{2. Öğretme Paradigmasından Öğrenme Paradigmasına Geçiş}

Etkili bir öğrenme ortamı, mesleki becerileri geliştirmek için belirli bir öğretme stratejisinin kullanılmasını gerektirmez. Pedagojik yaklaşımın başarısının gerçek ölçütü, bilginin verilme biçiminden bağımsız olarak ögrencilerde gerçekleşen öğrenme seviyesidir (French ve Coppage, 2003: 112). Öğretim ve öğrenim arasında ayrım yapmak çok önemlidir. Bir öğrenciye bir sorunun nasıl çözüleceği gösterildiğinde öğretim; öğrenci kendi problemini nasıl çözeceğini belirlediğinde ise öğrenim gerçekleşir (Mohamed ve Lashine, 2003: 9).

Muhasebenin sosyal, ahlaki, kültürel ve politik açılardan toplumu etkileyen ve toplumdan etkilenen bir yap1 olarak anlaşılması ve üst düzey genel yetkinliklerin geliştirilmesi, öğrencilerde derinlemesine öğrenmeyle mümkündür. Derinlemesine öğrenme, içeriğin ezberlenmesi ve aynısının yeniden yapılması ile karakterize edilen sığ öğrenme yaklaşımlarıyla karşılaştırıldığında, duyu ve anlam yaratma arayışı ile özdeşleşmiştir. Başarılı derin öğrenme stratejileri, fikirleri tecrübe ile ilişkilendirmeyi, bulguları ayrıştırmayı, kalıpları 
ve ilkeleri tanımlamayı, farklı bilgi alanları arasındaki karşılıklı ilişkileri anlamayı ve ilkeleri yeni durumlara uygulamayı içerir (Boyce vd., 2012: 55).

Öğretim elemanları, ezberlemeye ve ders kitabı kullanımına bağımlı olmayan, yaratıcı bir öğrenme sürecine uyum sağlamalıdır. Bu süreç, takım çalışmasına dayanmalı, öğrencileri gerçek şirketlere, gerçek olay analizlerine, sözlü sunumlara, derslere iş hayatından profesyonelleri katmaya ve teknolojiyi kullanmaya yönlendirmelidir (Mohamed ve Lashine, 2003: 9).

\subsection{Teknolojiyi Anlama ve Teknolojiden Yararlanma}

Teknoloji, iş modellerini ve işlemleri daha karmaşı hale getirmiş, ürün ömrünü kısaltmış ve iş dünyasındaki dinamik değişimin etkinleştirilmesini sağlamışı (Mohamed ve Lashine, 2003: 11). Anında geribildirim ve cevap talebi oluşturmuştur (French ve Coppage, 2003: 113). Derslerde teknolojinin, bir muhasebe elemanının çalışma şeklini, bilgi sağlama ve bilgiyi kullanma biçimini nasıl değiştirdiğini ve değiştirmeye devam edeceği vurgulanmalıdır. Öğrenciler, örneğin, teknolojinin bilgi edinme maliyetini nasıl düşürdüğünü anlamalı, ucuz bilginin çalışma hayatında ne anlama geldiğini bilmelidirler. Ayrıca, günlük iletişimden, karar alma için gerekli bilgilerin edinilmesine, stratejik ortaklıkların oluşturulmasına kadar her türlü faaliyet ve olayda teknolojinin işletmeye nasıl yardımcı olduğunu ve işletmeyi nasıl yönlendirdiğini anlamalıdırlar.

Muhasebe eğitiminde ve öğrenci becerilerinin geliştirilmesinde teknoloji kullanımında yaratıcı olmak gerekmektedir. Örneğin, belirli bir muhasebe alanındaki uzmanlarla interaktif dersler yapılabilir ya da sınırlı kaynaklar yüzünden açılamamış olan bazı seçmeli dersler açılabilir (French ve Coppage, 2003: 113).

\section{SONUÇ}

İşletmelerde üstün performansa ulaşmanın temel kaynağı uygun yetkinliklere sahip çalışanlardır. Küresel iş dünyasının kapsamı ve dinamikleri, muhasebe çalı̧̧anlarında bulunması gereken yetkinliklerde değişikliklere neden olmuştur. Günümüzde işverenler, çalışanlarının belirli teknik bilgi ve sektör bilgisine sahip olmanın yanı sıra "kalıpların dışında" düşünmelerini sağlayan çeşitli genel yetkinliklere sahip olmalarını beklemektedirler. Geleneksel muhasebe programları iyi bir muhasebeci oluşturabilirken, iş dünyası işletmelerine değer katabilecek çok yönlü bir çalışan istemektedir.

Muhasebe eğitiminin kalitesi, muhasebe mezunlarının değişen pazar taleplerini karşılama derecelerine bağlıdır. Muhasebe çalışanlarının değer teklifi, veriyi elde etmek ve analiz etmek, ilgili bilgileri bütünleştirmek, örgütün hedeflerini destekleyen karar alma süreçlerine katılmak ve sonuçların farklı paydaş grupları üzerindeki etkilerini izlemek için yetkinliklerini bütünleştirebilme yeteneğinden kaynaklanmaktadır. Farklı yetkinliklerin varlığı, iş hayatındaki farklı nitelikteki zorlukların üstesinden gelmeye yardımcı olduğu için işverenler tarafindan gerekli görülmektedir.

Küresel ve dijital çağa ayak uydurması ve değişen paydaş taleplerine cevap verebilmesi için muhasebe eğitiminde değişiklik ihtiyacı, özellikle son yıllarda sıklıkla dile getirilmektedir. Bu bağlamda beceri ve yetkinliklere daha fazla odaklanma, daha entegre 
öğrenme, değerlendirme yoluyla daha fazla hesap verebilirlik ve yaşam boyu öğrenim vurgusu da dahil olmak üzere, yüksek öğretimin değişmesi gerektiği vurgulanmaktadır.

$\mathrm{Bu}$ çalışmada muhasebe yetkinliklerine ilişsin teorik altyapı ortaya konulmuştur. Bu bağlamda çalışmanın kısıtı, literatür taramasına dayalı nitel bir çalışma olmasıdır. Türkiye'de yetkinlikler bağlamında muhasebe eğitiminin işveren beklentilerini karşılama yeterliliğini ve muhasebe ders programlarının yetkinlik kazandırma derecesini ölçen nicel çalışmalar farklı araştırmaların konusu olabilir.

\section{KAYNAKLAR}

Albrecht, W. Steve - Sack, Robert . J. (2000). "Accounting Education: Charting the Course through a Perilous Future", American Accounting Association: Accounting Education Series (Vol. 16). https://www2.aaahq.org/pubs/AESv16/toc.htm (Erişim: 10.02.2018)

American Institute of Certified Public Accountants (AICPA) (2017). (Erişim: 01.02.2018) https://www.aicpa.org/interestareas/accountingeducation/resources/accountingcore-competencies-functional.html

https://www.aicpa.org/interestareas/accountingeducation/resources/accounting-corecompetencies-personal.html

https://www.aicpa.org/interestareas/accountingeducation/resources/accounting-corecompetencies-business.html

Boyatzis, Richard. E. (2008), "Competencies in the 21st Century", Journal of Management Development, 27 (1), pp. 5-12.

Boyce, Gordon - Greer, Susan - Blair, Bill - Davids, Cindy. (2012), "Expanding the Horizons of Accounting Education: Incorporating Social and Critical Perspectives", Accounting Education, 21 (1), pp. 47-74.

Brewer, Peter C. - Sorensen, James E. - Stout, David E. (2014), "The Future of Accounting Education: Addressing the Competency Crisis”, Strategic Finance (August), pp. 28-37.

Bui, Binh - Porter, Brenda (2010), "The Expectation-Performance Gap in Accounting Education: An Exploratory Study”, Accounting Education, 19 (1-2), pp. 23-50.

Clanchy, John - Ballard, Brigid (1995), "Generic Skills in the Context of Higher Education”, Higher Education Research and Development, 14 (2), pp. 155-166.

Cranmer, Sue (2006), "Enhancing Graduate Employability: Best Intentions and Mixed Outcomes", Studies in Higher Education, 31(2), pp. 169-184.

CPA Canada (2012), "The CPA Competency Map: How to Qualify for the Canadian CPA Designation" https://www.cpacanada.ca/en/become-a-cpa/pathways-to-becoming-a-cpa/ national-education-resources/the-cpa-competency-map (Erişim: 01.02.2018).

Foley, Brendan (2007), "From Overhead to Asset: The Importance of People Skills", Accountancy Ireland, 39 (5), pp. 52-53. 
French, G. Richard - Coppage, Richard E. (2003), "A Strategic Model for Accounting Education", The Journal of Applied Business Research, 19 (2), pp. 107-116.

Frey, Carl Benedict - Osborne, Michael A. (2014), "Computers versus Humans", Policy Options, 35(1), pp. 26-29.

Gammie, Bob - Gammie, Elizabeth - Cargill, Erica (2002), "Personal Skills Development in the Accounting Curriculum", Accounting Education, 11(1), pp. 63-78.

Gray, Rob - Collison, David (2002), "Can't See the Wood for the Trees, Can't See the Trees for the Numbers? Accounting Education, Sustainability and the Public Interest", Critical Perspectives on Accounting, 13(5-6), pp. 797-836.

Groysberg, Boris - Kelly, L. Kevin - MacDonald, Bryan. (2011), "The New Path to the C-suite", Harvard Business Review (March), pp. 60-68.

Hood, Daniel (2015), "Losing Sleep: Leaders of the Profession on its Biggest Nightmares", Accounting Today, 29 (10), https://www.accountingtoday.com/news/losingsleep ( 25.01.2018).

Howieson, Bryan (2003), "Accounting Practice in the New Millennium: Is Accounting Education Ready to Meet the Challenge?", The British Accounting Review, 35(2), pp. 69103.

Humphrey, Christopher (2005), "In the Aftermath of Crisis: Reflections on the Principles, Values and Significance of Academic Inquiry in Accounting: Introduction", European Accounting Review, 14 (2), pp. 341-351.

Jackling, Beverley - De Lange, Paul (2009), "Do Accounting Graduates' Skills Meet the Expectations of Employers? A Matter of Convergence or Divergence", Accounting Education, 18 (4-5), pp. 369-385.

Lawson, Raef A. - Blocher, Edward J. - Brewer, Peter C. - Cokins, Gary - Sorensen, James E. - Stout, David E. - Sundem, Gary L. - Wolcott, Susan K. - Wouters, Marc J. F. (2014), "Focusing Accounting Curricula on Students' Long-Run Careers: Recommendations for an Integrated Competency-Based Framework for Accounting Education", Issues in Accounting Education, 29 (2), pp. 295-317.

Lawson, Raef A. - Blocher, Edward J. - Brewer, Peter C. - Morris, Jan Taylor - Stocks, Kevin D. - Sorensen, James E. - Stout, David E. - Wouters, Marc J. F. (2015), "Thoughts on Competency Integration in Accounting Education", Issues in Accounting Education, 30(3), pp. 149-171.

Lucas, Ursula - Cox, Paul - Croudace, Christopher - Milford, Peter (2004), "Who Writes This Stuff?: Students' Perceptions of Their Skills Development", Teaching in Higher Education, 9 (1), pp. 55-68.

Milner, Margaret - Hill, Wan Ying (2008), "Examining the Skills Debate in Scotland", International Journal of Management Education, 6 (3), pp. 13-20. 
Mohamed, Ehab K. - Lashine, Sherif H. (2003), “Accounting Knowledge and Skills and the Challenges of a Global Business Environment", Managerial Finance, 29 (7), pp. 3-16.

Pathways Commission (2012), "Charting a National Strategy for the Next Generation of Accountants". http://aaajournals.org/doi/abs/10.2308/iace-10300?code=aaan-site (15.01.2018).

Pincus, Karen V. - Stout, David E. - Sorensen, James E. - Stocks, Kevin D. - Lawson, Raef A. (2017), "Forces for Change in Higher Education and Implications for the Accounting Academy", Journal of Accounting Education. 40, pp. 1-18.

PricewaterhouseCoopers (2015), "The Evolution of Auditors: How Skillsets are Changing", https://www.pwc.com/us/en/cfodirect/publications/point-of-view/evolution-ofauditor-skills-technology-accounting.html (Erişim: 25.01.2018).

Siegel, Gary - Sorensen, James E. (1994), "What Corporate America Wants in EntryLevel Accountants: Some Methodological Concerns", Journal of Accounting Education. 14 (1), pp. 1-16.

Siegel, Gary - Sorensen, James E. - Klammer, Thomas - Richtermeyer, Sandra B. (2010), "The Ongoing Preparation Gap in Accounting Education: A Call to Action", Management Accounting Quarterly, 11 (3), pp. 41-52. 
